\title{
A meta-analysis on immune checkpoint inhibitor efficacy for advanced non-small cell lung cancer between East Asians versus non-East Asians
}

\author{
Siyu Peng ${ }^{1 \#}$, Ariel Fangting Ying ${ }^{2 \#}$, Bee Choo Tai ${ }^{3,4}$, Ross Andrew Soo ${ }^{5,6}$ \\ ${ }^{1}$ Department of Medicine, National University Health System, Singapore, Singapore; ${ }^{2}$ Health Services and System Research, Duke-NUS Medical \\ School, Singapore, Singapore; '3 Saw Swee Hock School of Public Health, ${ }^{4}$ Yong Loo Lin School of Medicine, National University of Singapore, \\ Singapore, Singapore; ${ }^{5}$ Department of Haematology-Oncology, National University Cancer Institute Singapore, National University Health System, \\ Singapore, Singapore; ${ }^{6}$ Cancer Science Institute, Singapore, Singapore \\ Contributions: (I) Conception and design: RA Soo, S Peng, AF Ying; (II) Administrative support: None; (III) Provision of study materials or patients: \\ None; (IV) Collection and assembly of data: S Peng, AF Ying; (V) Data analysis and interpretation: S Peng, AF Ying; (VI) Manuscript writing: All \\ authors; (VII) Final approval of manuscript: All authors. \\ "These authors contributed equally to this work. \\ Correspondence to: Ross Andrew Soo. Department of Haematology-Oncology, National University Cancer Institute Singapore, National University \\ Health System, 1E Kent Ridge Road, NUHS Tower Block Level 7, Singapore 119228, Singapore. Email: ross_soo@nuhs.edu.sg.
}

Background: We conducted a meta-analysis to assess the efficacy of immune checkpoint inhibitors (ICIs) (PD-1/L1 and CTLA-4 inhibitors) in first and subsequent lines in East Asians and non-East Asians.

Methods: We searched PubMed-MEDLINE, Embase and Scopus, from inception to 20 Sep 2019, and reviewed major conferences' abstracts, for randomised controlled trials of ICI in advanced-stage NSCLC (Stage IIIB or IV) without EGFR mutation that reported hazard ratios (HRs) stratified by geographical region including the region "Asia" or "East Asia". The primary outcome measures were overall survival (OS) and progression-free survival (PFS). The pooled HR and its 95\% confidence interval (CI) for OS and PFS in East Asians and non-East Asians were calculated using a random effect model and the difference compared using an interaction test.

Results: A total of 5,465 patients from 7 randomised controlled trials involving CTLA-4 and/or PD-1/L1 inhibitors were included, with 1,740 (32\%) East Asians and 3,725 (68\%) non-East Asians. ICI was associated with an improvement in OS and PFS for both East Asian (OS HR, 0.74; 95\% CI, 0.65-0.85; PFS HR, 0.56; 95\% CI, 0.40-0.79) and non-East Asian patients (OS HR, 0.78; 95\% CI, 0.72-0.85; PFS HR, 0.69; 95\% CI, 0.56-0.85), with no significant difference between the two groups $\left(\mathrm{P}_{\text {interaction }}=0.55\right.$ for OS; $\mathrm{P}_{\text {interaction }}=0.33$ for PFS). Subgroup analyses showed a statistically significant superior PFS (but not OS) for East Asians than non-East Asians in trials that used immune checkpoint inhibitor in the first-line treatment $\left(\mathrm{P}_{\text {interaction }}=0.02\right)$. No significant regional difference was found in further subgroups of pure ICI and combination of ICI with chemotherapy.

Conclusions: There is no significant difference in response to ICI between East Asians and non-East Asians with advanced stage NSCLC, and the statistically significant subgroup difference in PFS in the first line use of ICI may not be clinically significant.

Keywords: CTLA-4; East Asia; meta-analysis; non-small cell lung cancer (NSCLC); PD-1/L1

Submitted Feb 12, 2020. Accepted for publication Jun 11, 2020.

doi: $10.21037 /$ tlcr-20-246

View this article at: http://dx.doi.org/10.21037/tlcr-20-246 


\section{Introduction}

The advent of immune checkpoint inhibitors (ICIs) in the past decade has altered the treatment paradigm in patients with advanced non-small cell lung carcinoma (NSCLC), leading to ICIs being incorporated into clinical practice guidelines $(1,2)$. However, the majority of these guidelines are based on clinical trials that focused on mainly nonEast Asian populations (3). It is well-known that East Asian NSCLC patients possess a different clinical and genetic profile from non-East Asians, leading to different treatment recommendations (4-6). In terms of environmental factors, studies have shown that East Asian NSCLC patients are more likely to be non-smokers than non-East Asians (7), and never-smokers have been shown to respond poorer to ICI (8).

In terms of genomic differences, East Asian patients have been found to have up to 2.5 times higher rate of Epidermal Growth Factor Receptor (EGFR) mutations than non-East Asians (9). Current evidence suggests that ICIs are ineffective in such patients as oncogene-addicted NSCLC tends to be less immunogenic with an uninflamed tumour micro-environment (10-12). As such, ICI are not recommended as the first line therapy for patients with oncogene mutation (13). Apart from the prevalence of oncogene mutation, there are other genetic predictive factors that may differ between East Asians and nonEast Asians, such as programmed death ligand 1 (PD-L1) expression, tumour mutation burden (TMB) and gene expression profile score $(6,14)$. Other potentially predictive biological factors, such as immune cell populations, development of anti-drug antibodies and the microbiome may differ between East Asians and non-East Asians as well $(15,16)$.

Despite existing evidence that NSCLC in East Asians is different from that in non-East Asians, few studies have directly compared the response to ICIs between East Asian and non-East Asian populations, likely due to the lack of patient enrolment from Asian region (17).

Therefore, in this meta-analysis, we aim to evaluate whether ICIs (PD-1/L1 and CTLA-4 inhibitors) exhibit different efficacies in EGFR wild-type East Asian versus non-East Asian advanced NSCLC patients, measured in terms of overall survival (OS) and progression-free survival (PFS).

\section{Methods}

\section{Search strategy}

Our systemic review and meta-analysis followed the
Preferred Reporting Items for Systematic Reviews and Meta-analyses (PRISMA) guidelines (18). Detailed information on methods is available in the Supplementary material.

Two investigators (SP and AFY) independently searched, without language restriction, PubMed-MEDLINE, Embase and Scopus for Phase II and III randomised controlled trials (RCTs) published since the inception of each database to 20 September 2019. In addition, we reviewed abstracts and presentations from major conference proceedings such as the American Society of Clinical Oncology, the World Conference on Lung Cancer and the European Society for Medical Oncology from 2013 to September 2019 to identify unpublished studies.

\section{Selection criteria}

We included Phase II and III RCTs that: (I) recruited East Asian and non-East Asian patients aged 18 and above with advanced NSCLC (Stage IIIB and IV) without EGFR mutation; (II) evaluated the efficacy of ICIs either administered alone or in combination with other ICIs or chemotherapy, as compared to that of standard chemotherapy; and (III) reported outcomes that include subgroup OS or PFS classified by geographical regions including the region "East Asia" or "Asia".

Trials were excluded if they were single-arm studies, enrolled patients with EGFR mutation, conducted only in East Asian or non-East Asian regions, did not report a subgroup outcome from Asia, used a combination of ICIs with other targeted therapy or radiotherapy in the intervention arm, or compared different regimens of ICI or one ICI versus another type of ICI. For trials that did not report outcomes by regions, we attempted to contact the authors for the information, failing which the trials were excluded from quantitative analysis. We also compiled a table of ongoing studies that fulfilled our inclusion criteria but have yet to complete recruitment or publish regional survival data.

\section{Data extraction}

The same investigators independently extracted data from the selected studies and discrepancies were resolved by consensus of all investigators. Information extracted include: trial name, name of first author, year of publication, type of ICI, line of therapy, histology, stage of NSCLC, level of PD-L1 expression, median or minimum duration of 
follow-up, median age, the original regional classification, all the countries of recruitment, total number of patients as well as number in East Asian and non-East Asian subgroups, and the hazard ratio (HR) estimate of treatment effect for OS and PFS in East Asians or non-East Asians. We searched for but could not find regional subgroup data of Objective Response Rate in the included trials. "East Asia" is defined as the countries or regions from Eastern Asia with or without those from South-Eastern Asia (19). "Non-East Asia" is defined as the sum of all the other regions, such as North America, Europe, and South America. We have compiled a list of all the patient recruitment sites classified by region for the included studies (Tables $S 1, S 2$ ).

\section{Quality assessment}

The study quality was assessed using the Risk of Bias Tool (20) in Review Manager version 5.3 (RevMan 5.3) software by Nordic Cochrane Centre, and scored according to the domains of selection bias, performance bias, detection bias, attrition bias and reporting bias. Publication bias was evaluated by funnel plots.

\section{Data analysis}

The primary endpoint was the efficacy of ICIs between East Asians and non-East Asians, measured in terms of HR for OS and PFS, respectively.

We used RevMan 5.3 to calculate the pooled HR for OS and PFS for the East Asians and non-East Asians via the inverse variance technique. First, in studies that did not have a single "non-East Asian" subgroup, we used fixed effect models to obtain a pooled estimate of survival HR from different regions within a single study. Then, we applied random effects models to generate the forest plots across all the included studies, in view of clinical heterogeneity due to different trial designs. Lastly, we conducted the test of interaction to determine if a significant subgroup difference exists between the pooled HR for East Asians versus nonEast Asians.

Further pre-specified subgroup analyses (21) were conducted to assess the potential association of effect modifiers with region and survival outcome. Subgroups analysed include the line of therapy (first line or second line and beyond) and the type of therapy (ICI monotherapy or doublet therapy versus ICI in combination with chemotherapy). This was done via the test of interaction (test of subgroup differences) that produced the interaction
$\mathrm{P}$ value and $\mathrm{I}^{2}$ for heterogeneity. All reported $\mathrm{P}$ values were 2 -sided and $\mathrm{P}=0.05$ indicated statistical significance.

\section{Results}

\section{Study selection}

We obtained 4,465 publications from the literature search and three additional records from conference proceedings. After abstract review and removal of duplicates, 21 potentially relevant articles were selected 22 for full text screen. A further 15 trials were excluded: two trials included patients with EGFR mutation, three did not recruit patients from East Asia, two did not have a distinct East Asia or Asia regional subgroup, and eight others lacked regional subgroup data. Figure 1 shows the seven RCTs included in the final analysis (22-29). Out of these seven studies, two of them included updated subgroup results from conference presentations, namely both OS and PFS in IMpower 132 (22) and CheckMate-078 (29). The remaining five published their most updated results in journals, namely PFS in CheckMate-227 (24), OS in KEYNOTE-042 (25), both OS and PFS in KEYNOTE-407 (26), both OS and PFS in JAVELIN Lung 200 (23), as well as both OS (27) and PFS (28) in KEYNOTE-024. Of note, although CheckMate-227 published updated OS results in November 2019, there was no available regional subgroup data (30). Also, although KEYNOTE-042 reported the final OS analysis after 6 additional calendar months of follow-up at the European Lung Cancer Congress 2019 (31), the regional subgroup information was incomplete and insufficient for analysis. Hence, we used the preliminary but complete data from the original paper for KEYNOTE-042 (25).

In view of the rapidly expanding literature, we also created a "watch-list" of ongoing trials that recruited patients from East Asian countries, available in Table S3 (32-40).

\section{Study characteristics}

The study characteristics are presented in Table 1. All trials were Phase III involving patients with advanced stage NSCLC (Stage IIIB or Stage IV or recurrent) without EGFR mutation. The median follow-up time was about 11 months, with the longest follow-up being KEYNPTE-024 OS (27) with 25.2 months and the shortest being KEYNOTE-407 with 7.8 months (26). In terms of choice of inhibitor, there were four trials using PD-1 inhibitors: one on nivolumab, CheckMate-078 (29) and 


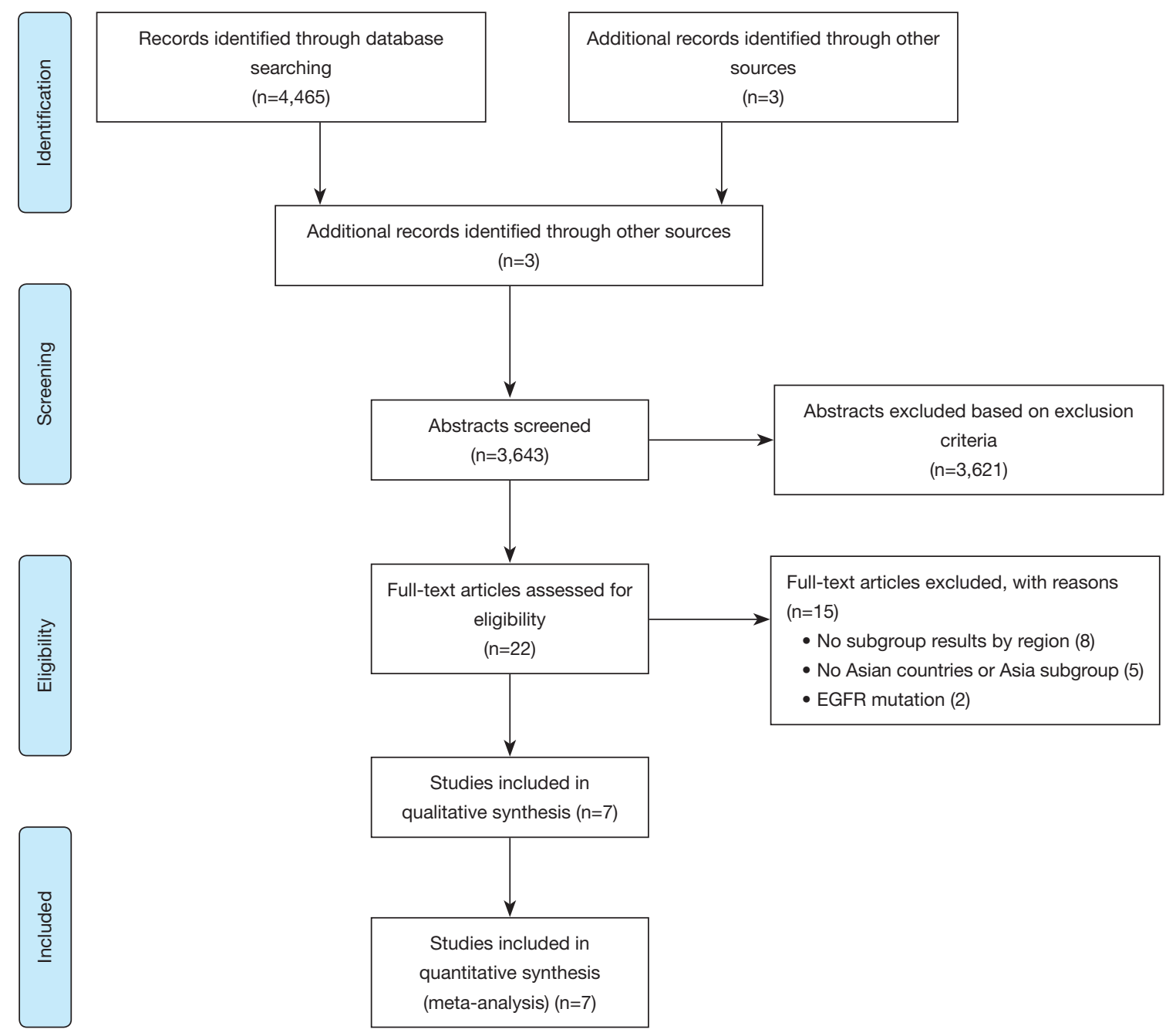

Figure 1 PRISMA flow diagram for the meta-analysis.

three on pembrolizumab, KEYNOTE-024, 042 and 407 (25-28). There were two trials using PD-L1 inhibitors: one on atezolizumab, IMpower 132 (22) and one on avelumab, JAVELIN Lung 200 (23). There was also one trial using a combination of PD-1 inhibitor nivolumab and CTLA-4 inhibitor ipilimumab, CheckMate-227 (24).

A total of 5,465 patients (median age 64 years, consistent across studies) were included, of which 1,740 (32\%) were East Asians and 3,725 (68\%) were non-East Asians. Most trials consisted of predominantly non-East Asian patients except CheckMate-078 (29), which had a predominantly Chinese population. The non-East Asia category is a heterogeneous group that consists of the sum of different original regional classifications adopted by the trials, which sometimes overlap, such as non-East Asia (56\%), United
States and Western Europe (3\%), Rest of the world (3\%) and Europe (3\%) (Table S1 and Figure S1). Six trials provided regional subgroup data on OS (5,166 patients) and six trials on PFS (2,774 patients). Stratified randomisation by region was conducted in three trials, namely KEYNOTE-024, KEYNOTE-042, and KEYNOTE-407 (25-28).

In terms of outcomes reported, most of the trials reported superior outcomes, be it PFS and/or OS, for ICIs over chemotherapy. However, IMpower 132 reported superiority of atezolizumab combined with chemotherapy in PFS but not in OS (22). KEYNOTE-042 reported superiority of pembrolizumab monotherapy in OS but not in PFS (25). In addition, JAVELIN Lung 200 reported that the use of anti-PD-L1 avelumab was not superior to chemotherapy for both OS and PFS (23). 


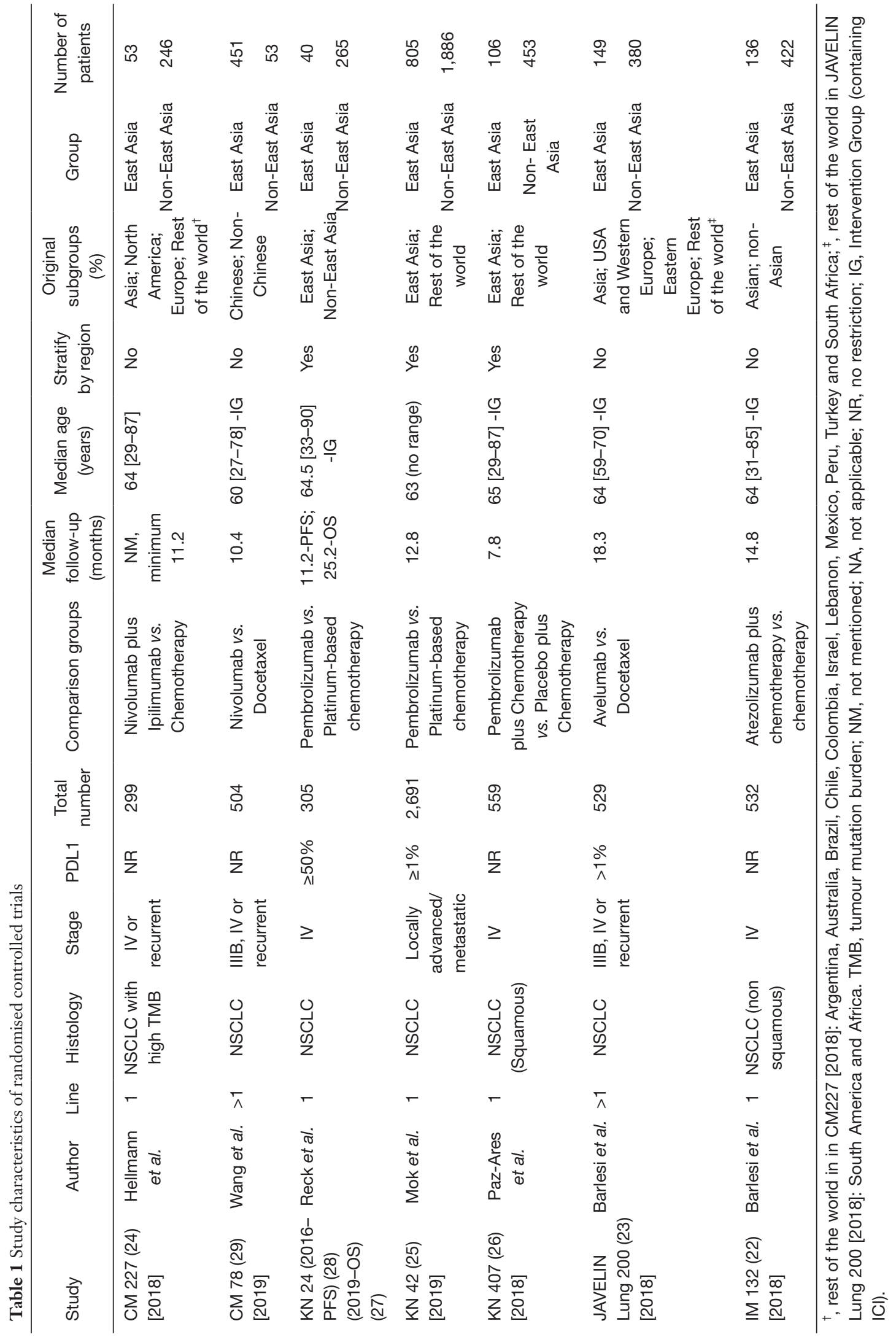




\section{Quality assessment (Risk of bias)}

All trials included random sequence generation and allocation concealment (except unreported information in one trial) to reduce selection bias (Figure S2). However, six trials did not blind the treatment allocation to participants and personnel, leading to a higher risk of performance bias. Blinding of outcome assessment was implemented in a total of four trials, but not in the remaining three trials, leading to risk of detection bias. All trials were at low risk of attrition and reporting bias. The funnel plots for both OS (Figure $S 3 A$ ) and PFS (Figure $S 3 B$ ) are largely symmetrical, indicating minimal publication bias.

\section{Quantitative analysis}

In the six studies that reported OS, the statistical heterogeneity was low in both the East Asian group $\left(\mathrm{I}^{2}=0 \%\right)$ and the non-East Asian group $\left(\mathrm{I}^{2}=0 \%\right.$ ) (Figure $\left.2 A\right)$, compared with chemotherapy, ICIs showed an improvement in OS in both East Asians [HR, 0.74; 95\% confidence interval (CI), 0.65-0.85] and non-East Asians (HR, 0.78; 95\% CI, 0.72$0.85)$. There was no difference in OS benefit between East Asians and non-East Asians ( $\mathrm{P}$ for interaction $=0.55$ ).

In the six studies that reported PFS, there was moderate statistical heterogeneity within both the East Asian group $\left(\mathrm{I}^{2}=67 \%\right)$ and the non-East Asian group $\left(\mathrm{I}^{2}=66 \%\right)$ (Figure $2 B$ ). An improvement in PFS was observed in both East Asians (HR, 0.56; 95\% CI, 0.40-0.79) and non-East Asians (HR, $0.69 ; 95 \%$ CI, 0.56-0.85) treated with ICI. There was no significant difference in PFS benefit between the East Asians and non-East Asians ( $\mathrm{P}$ for interaction $=0.33$ ).

Compared to OS, the heterogeneity in PFS is much higher. The largest trial included in our study, KEYNOTE-042 (25) which reported only OS, recruited far more patients $(n=2,691)$ than all the other trials $(n=299-578)$. Hence, the heterogeneity in OS is very low (overall $\mathrm{I}^{2}=0 \%$ ) (Figure 2A). However, for PFS (Figure 2B), the weight distribution is more evenly distributed across the various trials, including an additional trial CheckMate-227 (24). Hence, the heterogeneity in PFS is much higher (overall $\left.\mathrm{I}^{2}=64 \%\right)$. In addition, there is less inter-study variation in OS than PFS. In East Asians, the 95\% CI for OS was $0.65-0.85$ as compared to that of $0.40-0.79$ for PFS. In non-East Asians, the $95 \%$ CI for OS was $0.72-0.85$ as compared to that of $0.56-0.85$ for PFS. Possible reasons include higher risk of assessment bias in PFS analysis, such as lack of blinding in most trials and different timings of tumour imaging to assess disease progression.

\section{Subgroup analysis}

\section{Line of therapy}

Of the eight studies included in the meta-analysis, six examined the use of ICI in the first-line setting. Further subgroup analysis by the line of treatment for response in terms of OS (Figure $3 A$ ) did not show any regional differences. In first line, both East Asians (HR, 0.65; 95\% CI, 0.47-0.90) and non-East Asians (HR, 0.76; 95\% CI, 0.69-0.83) saw an improvement in OS, with $\mathrm{P}$ for interaction $=0.37$. In second or higher lines, East Asians (HR, 0.75; 95\% CI, 0.63-0.91) saw a statistically significant improvement to their OS, while non-East Asians (HR, 0.93; 95\% CI, 0.73-1.19) did not, although this difference was not statistically significant $(\mathrm{P}$ for interaction $=0.17$ ).

Looking at first line therapy in terms of PFS (Figure $3 B$ ), East Asians (HR, 0.42; 95\% CI, 0.32-0.56) saw a statistically significant benefit ( $\mathrm{P}$ for interaction $=0.02$ ) as compared to non-East Asians (HR, 0.60; 95\% CI, 0.53-0.68). This significance was not seen in subsequent lines; both East Asians (HR, 0.83; 95\% CI, 0.59-1.18) and non-East Asians (HR, 1.00; 95\% CI, 0.78-1.27) saw a non-statistically significant improvement in their PFS.

\section{Type of therapy}

Of the included trials, four of them examined ICI monotherapy (CheckMate-78, KEYNOTE-024, KEYNOTE-042, and JAVELIN Lung 200) (23,25,27-29), one examined ICI doublet therapy (CheckMate-227) (30), and the last two examined ICI in combination with chemotherapy (KEYNOTE-407 and IMpower 132) (26,41). Further subgroup analysis was performed stratifying by whether the trial examined pure ICI (both monotherapy and doublet therapy) or ICI in combination with chemotherapy.

In the pure ICI subgroup, both East Asians (HR, 0.76; 95\% CI, 0.67-0.87) and non-East Asians (HR, 0.79; 95\% CI, 0.71-0.87) saw an improvement to their OS (Figure 4A), but there was no difference between the two subgroups ( $\mathrm{P}$ for interaction $=0.72$ ). Similarly, in the ICI-chemotherapy combination subgroup, the OS was similar between East Asians (HR, 0.56; 95\% CI, 0.36-0.89) and non-East Asians (HR, 0.77; 95\% CI, 0.63-0.93), with $\mathrm{P}$ for interaction $=0.22$.

In terms of PFS (Figure $4 B$ ), there was suggestion of improvement in the pure ICI subgroup for both East Asians (HR, 0.64; 95\% CI, 0.41-0.99) and non-East Asians (HR, 0.76 ; $95 \%$ CI, 0.52-1.09), but there was no difference 


\begin{tabular}{|c|c|c|c|c|c|}
\hline \multicolumn{2}{|c|}{ Study or Subgroup Sample Size } & Weight & \multirow[t]{2}{*}{$\begin{array}{l}\text { Hazard Ratio } \\
\text { IV, Random, } 95 \% \mathrm{CI} \\
\end{array}$} & \multicolumn{2}{|c|}{$\begin{array}{c}\text { Hazard Ratio } \\
\text { IV, Random, } 95 \% \mathrm{CI}\end{array}$} \\
\hline \multicolumn{3}{|c|}{ Overall Survival: East Asia } & & & \\
\hline Reck 2016, KN24 & 40 & $0.4 \%$ & $0.35[0.12,1.02]$ & & \\
\hline Paz-Ares 2018, KN407 & 106 & $1.0 \%$ & $0.44[0.22,0.88]$ & & \\
\hline Barlesi 2018, IM132 & 136 & $1.4 \%$ & $0.68[0.37,1.25]$ & & \\
\hline Barlesi 2018, J200 & 149 & $3.4 \%$ & $0.84[0.57,1.24]$ & & . \\
\hline Wang 2019, CM78 & 451 & $11.1 \%$ & $0.73[0.59,0.90]$ & $\longrightarrow$ & \\
\hline Mok 2019, KN42 & 805 & $13.2 \%$ & $0.79[0.65,0.96]$ & & \\
\hline Subtotal $(95 \% \mathrm{CI})$ & 1687 & $30.6 \%$ & $0.74[0.65,0.85]$ & & \\
\hline \multicolumn{6}{|c|}{ Heterogeneity: $\mathrm{Tau}^{2}=0.00 ; \mathrm{Chi}^{2}=4.97, \mathrm{df}=5(\mathrm{P}=0.42) ; \mathrm{I}^{2}=0 \%$} \\
\hline \multicolumn{6}{|c|}{ Overall Survival: Non-East Asia } \\
\hline Wang 2019, CM78 & 53 & $1.2 \%$ & $1.02[0.54,1.93]$ & & \\
\hline Reck 2016, KN24 & 265 & $5.1 \%$ & $0.67[0.49,0.92]$ & & \\
\hline Paz-Ares 2018, KN407 & 453 & $5.5 \%$ & $0.69[0.51,0.93]$ & & \\
\hline Barlesi 2018, J200 & 380 & $7.5 \%$ & $0.92[0.71,1.19]$ & & \\
\hline Barlesi 2018, IM132 & 442 & $8.2 \%$ & $0.82[0.64,1.05]$ & 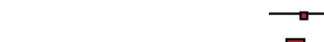 & \\
\hline Mok 2019, KN42 & $\begin{array}{l}1886 \\
3479\end{array}$ & $\begin{array}{l}41.8 \% \\
69.4 \%\end{array}$ & $0.77[0.69,0.86]$ & & \\
\hline \multicolumn{6}{|c|}{ Heterogeneity: $\mathrm{Tau}^{2}=0.00 ; \mathrm{Chi}^{2}=3.99, \mathrm{df}=5(P=0.55) ; \mathrm{I}^{2}=0 \%$} \\
\hline Total $(95 \% \mathrm{Cl})$ & 5166 & $100.0 \%$ & $0.77[0.72,0.83]$ & 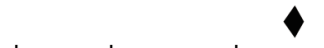 & \\
\hline \multicolumn{5}{|c|}{ 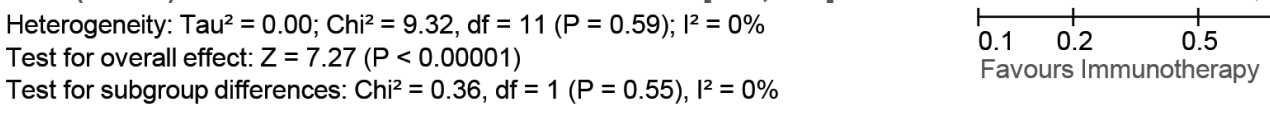 } & $\begin{array}{llll} & 2 & 5 & 10 \\
& & & \text { Favours [control] }\end{array}$ \\
\hline
\end{tabular}

B

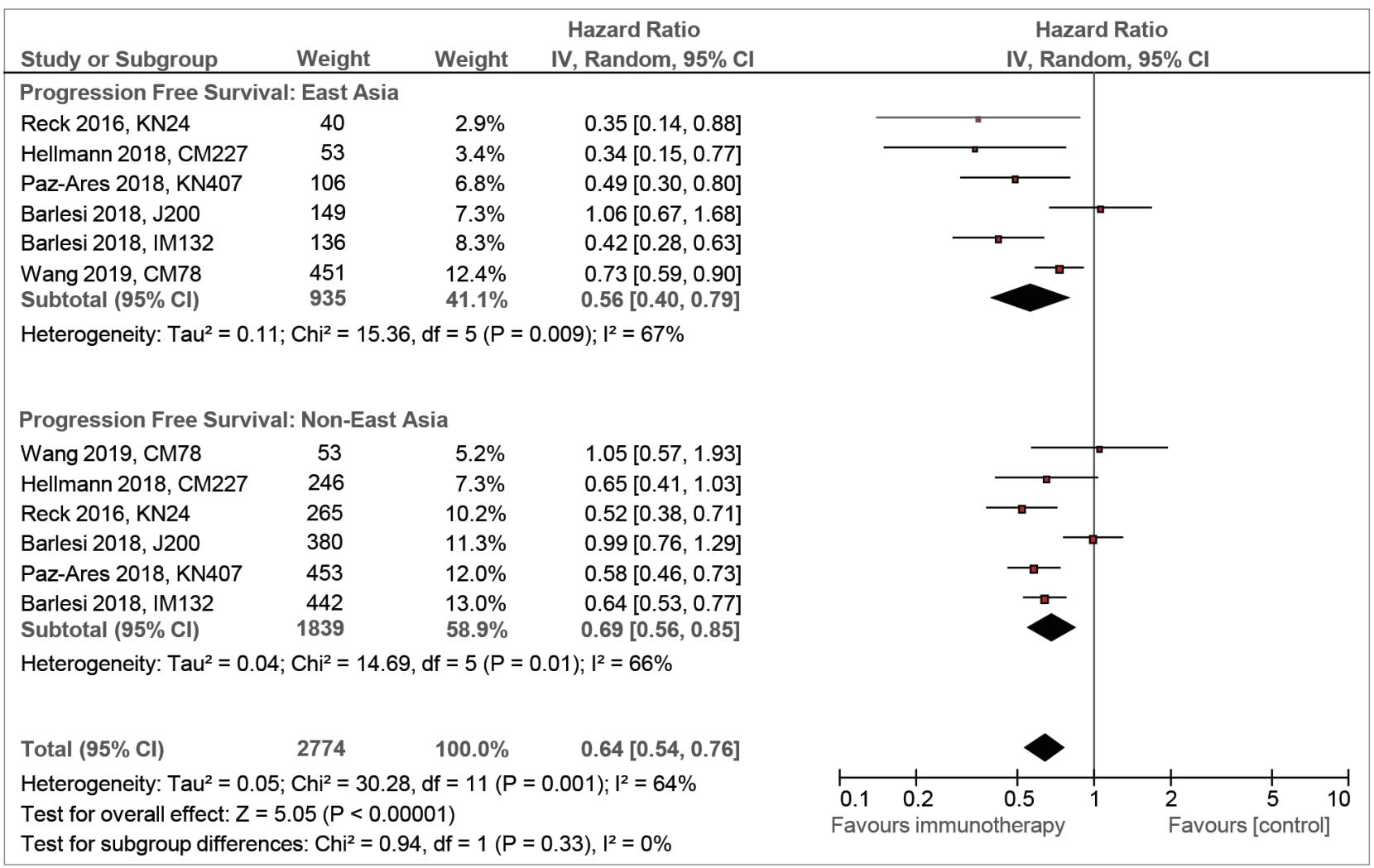

Figure 2 Comparison of regional subgroup difference in OS (A) and PFS (B). 
A

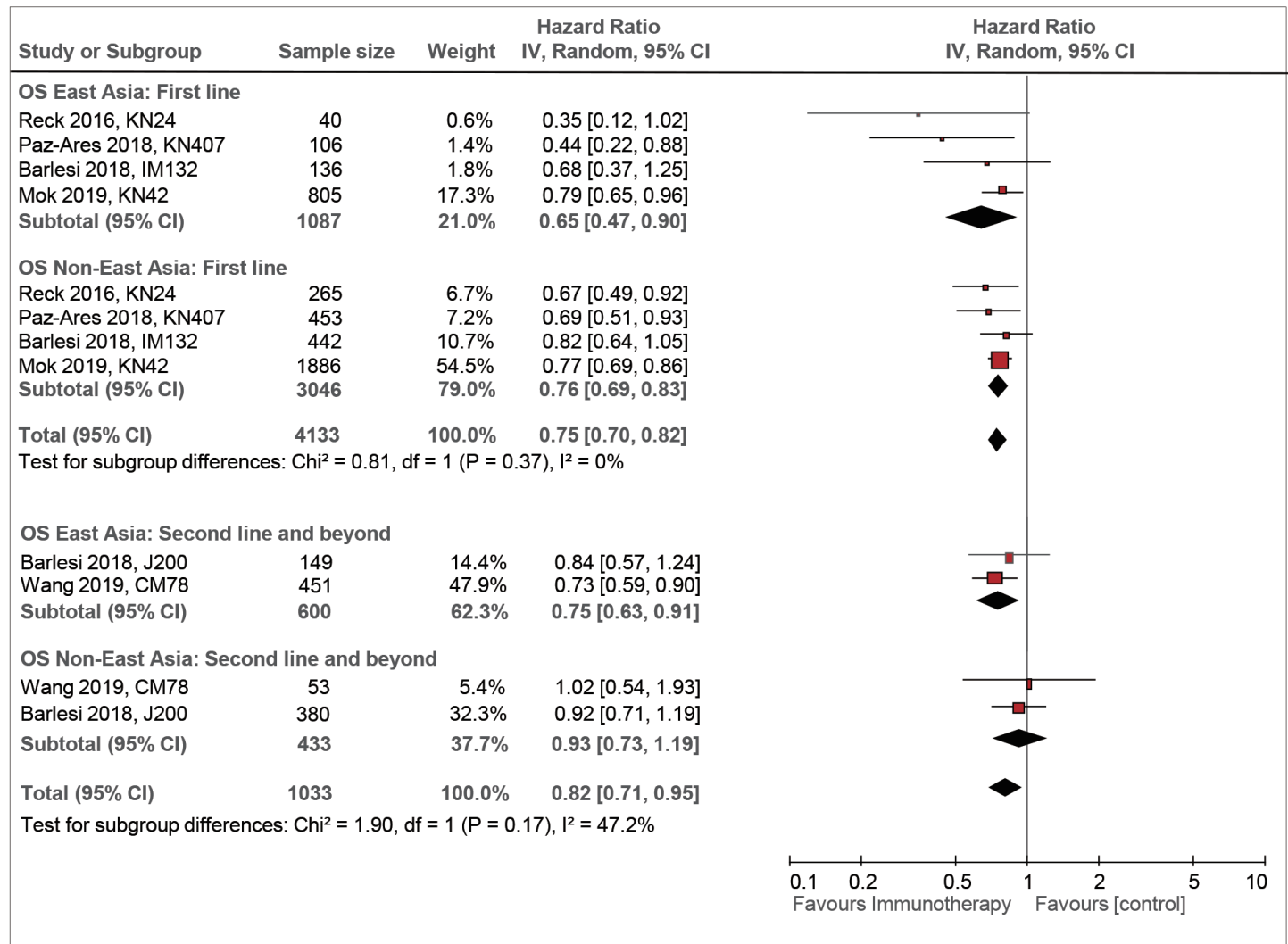

B

\begin{tabular}{|c|c|c|c|c|c|}
\hline \multirow{3}{*}{$\begin{array}{l}\text { Study or Subgroup } \\
\text { PFS East Asia: First line } \\
\text { Reck 2016. KN24 }\end{array}$} & Sample size & Weight & $\begin{array}{l}\text { Hazard Ratio } \\
\text { IV, Random, } 95 \% \mathrm{CI}\end{array}$ & \multicolumn{2}{|c|}{$\begin{array}{c}\text { Hazard Ratio } \\
\text { IV, Random, } 95 \% \mathrm{Cl}\end{array}$} \\
\hline & & & & & \\
\hline & $\begin{array}{l}40 \\
53\end{array}$ & $1.7 \%$ & $0.35[0.14,0.88]$ & & \\
\hline Hellmann 2018, CM227 & 53 & $2.1 \%$ & $0.34[0.15,0.77]$ & & \\
\hline Paz-Ares 2018, KN407 & 106 & $5.9 \%$ & $0.49[0.30,0.80]$ & $\longrightarrow$ & \\
\hline Barlesi 2018, IM132 & 136 & $8.6 \%$ & $0.42[0.28,0.63]$ & & \\
\hline Subtotal $(95 \% \mathrm{Cl})$ & 335 & $18.3 \%$ & $0.42[0.32,0.56]$ & & \\
\hline \multicolumn{6}{|c|}{ PFS Non-East Asia: First line } \\
\hline Hellmann 2018, CM227 & 246 & $6.7 \%$ & $0.65[0.41,1.03]$ & & \\
\hline Reck 2016, KN24 & 265 & $14.1 \%$ & $0.52[0.38,0.71]$ & & \\
\hline $\begin{array}{l}\text { Paz-Ares 2018, KN407 } \\
\text { Barlesi 2018, IM132 }\end{array}$ & $\begin{array}{l}453 \\
442\end{array}$ & $\begin{array}{l}24.8 \% \\
36.1 \%\end{array}$ & $\begin{array}{l}0.58[0.46,0.73] \\
0.64[0.53,0.77]\end{array}$ & $\rightarrow$ & \\
\hline Subtotal $(95 \% \mathrm{Cl})$ & 3046 & $81.7 \%$ & $0.60[0.53,0.68]$ & & \\
\hline Total $(95 \% \mathrm{Cl})$ & 4133 & $100.0 \%$ & $0.56[0.50,0.63]$ & & \\
\hline \multicolumn{6}{|c|}{ Test for subgroup differences: $\mathrm{Chi}^{2}=5.03, \mathrm{df}=1(P=0.02), \mathrm{I}^{2}=80.1 \%$} \\
\hline \multicolumn{6}{|c|}{ PFS East Asia: Second line and beyond } \\
\hline Barlesi 2018, J200 & 149 & $15.8 \%$ & $1.06[0.67,1.68]$ & & \\
\hline Wang 2019, CM78 & 451 & $41.2 \%$ & $0.73[0.59,0.90]$ & & \\
\hline Subtotal $(95 \% \mathrm{Cl})$ & 600 & $57.0 \%$ & $0.83[0.59,1.18]$ & & \\
\hline \multicolumn{6}{|c|}{ PFS Non-East Asia: Second line and beyond } \\
\hline Wang 2019, CM78 & 53 & $9.8 \%$ & $1.05[0.57,1.93]$ & & \\
\hline Barlesi 2018, J200 & 380 & $33.2 \%$ & $0.99[0.76,1.29]$ & & \\
\hline Subtotal $(95 \% \mathrm{Cl})$ & 433 & $43.0 \%$ & $1.00[0.78,1.27]$ & & \\
\hline Total $(95 \% \mathrm{Cl})$ & 1033 & $100.0 \%$ & $0.89[0.72,1.09]$ & & \\
\hline \multicolumn{6}{|c|}{ Test for subgroup differences: $\mathrm{Chi}^{2}=3.48, \mathrm{df}=1(\mathrm{P}=0.06), \mathrm{I}^{2}=71.2 \%$} \\
\hline & & & & $\begin{array}{lll}0.1 & 0.2 & 0.5 \\
\text { Favours immunotherapy }\end{array}$ & $\begin{array}{lcc}2 & 5 & 10 \\
\text { Favours [control] }\end{array}$ \\
\hline
\end{tabular}

Figure 3 Comparison of regional subgroup difference in OS (A) and PFS (B) according to first versus subsequent lines of therapy. 
A

\begin{tabular}{|c|c|c|c|c|c|}
\hline Study or Subgroup & Sample size & Weight & $\begin{array}{l}\text { Hazard Ratio } \\
\text { IV, Random, } 95 \% \text { CI }\end{array}$ & $\begin{array}{l}\text { Hazar } \\
\text { IV, Rand }\end{array}$ & $\begin{array}{l}\text { rd Ratio } \\
\text { dom, } 95 \% \mathrm{Cl}\end{array}$ \\
\hline \multicolumn{6}{|l|}{ OS East Asia: Pure ICI } \\
\hline Reck 2016, KN24 & 40 & $0.5 \%$ & $0.35[0.12,1.02]$ & & \\
\hline Barlesi 2018, J200 & 149 & $4.0 \%$ & $0.84[0.57,1.24]$ & & - \\
\hline Wang 2019, CM78 & 451 & $13.3 \%$ & $0.73[0.59,0.90]$ & $\rightarrow$ & \\
\hline Mok 2019, KN42 & 805 & $15.8 \%$ & $0.79[0.65,0.96]$ & 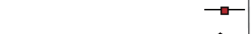 & \\
\hline Subtotal $(95 \% \mathrm{Cl})$ & 1445 & $33.6 \%$ & $0.76[0.67,0.87]$ & 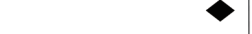 & \\
\hline \multicolumn{6}{|c|}{ OS Non-East Asia: Pure ICI } \\
\hline Wang 2019, CM78 & 53 & $1.5 \%$ & $1.02[0.54,1.93]$ & & \\
\hline Reck 2016, KN24 & 265 & $6.1 \%$ & $0.67[0.49,0.92]$ & & \\
\hline Barlesi 2018, J200 & 380 & $8.9 \%$ & $0.92[0.71,1.19]$ & 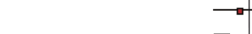 & \\
\hline Mok 2019, KN42 & 1886 & $49.9 \%$ & $0.77[0.69,0.86]$ & 뭄 & \\
\hline Subtotal $(95 \% \mathrm{Cl})$ & 2584 & $66.4 \%$ & $0.79[0.71,0.87]$ & 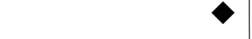 & \\
\hline Total $(95 \% \mathrm{Cl})$ & 4029 & $100.0 \%$ & $0.78[0.72,0.84]$ & $\bullet$ & \\
\hline \multicolumn{6}{|c|}{ Test for subgroup differences: $\mathrm{Chi}^{2}=0.13, \mathrm{df}=1(P=0.72), \mathrm{I}^{2}=0 \%$} \\
\hline \multicolumn{6}{|c|}{ OS East Asia: Combination ICI with Chemotherapy } \\
\hline Paz-Ares 2018, KN407 & 106 & $6.8 \%$ & $0.44[0.22,0.88]$ & & \\
\hline Barlesi 2018, IM132 & 136 & $8.8 \%$ & $0.68[0.37,1.25]$ & & \\
\hline Subtotal $(95 \% \mathrm{Cl})$ & 242 & $15.5 \%$ & $0.56[0.36,0.89]$ & & \\
\hline \multicolumn{6}{|c|}{ OS Non-East Asia: Combination ICI with Chemotherapy } \\
\hline Paz-Ares 2018, KN407 & 453 & $34.4 \%$ & $0.69[0.51,0.93]$ & $\longrightarrow$ & \\
\hline Barlesi 2018, IM132 & 442 & $50.1 \%$ & $0.82[0.64,1.05]$ & & \\
\hline Subtotal $(95 \% \mathrm{Cl})$ & 895 & $84.5 \%$ & $0.77[0.63,0.93]$ & & \\
\hline Total $(95 \% \mathrm{Cl})$ & 1137 & $100.0 \%$ & $0.73[0.61,0.87]$ & & \\
\hline \multicolumn{6}{|c|}{ Test for subgroup differences: $\mathrm{Chi}^{2}=1.48, \mathrm{df}=1(\mathrm{P}=0.22), \mathrm{I}^{2}=32.2 \%$} \\
\hline & & & & 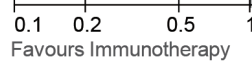 & $\begin{array}{lcr}2 & 5 & 10 \\
& \text { Favours [control] }\end{array}$ \\
\hline
\end{tabular}

B

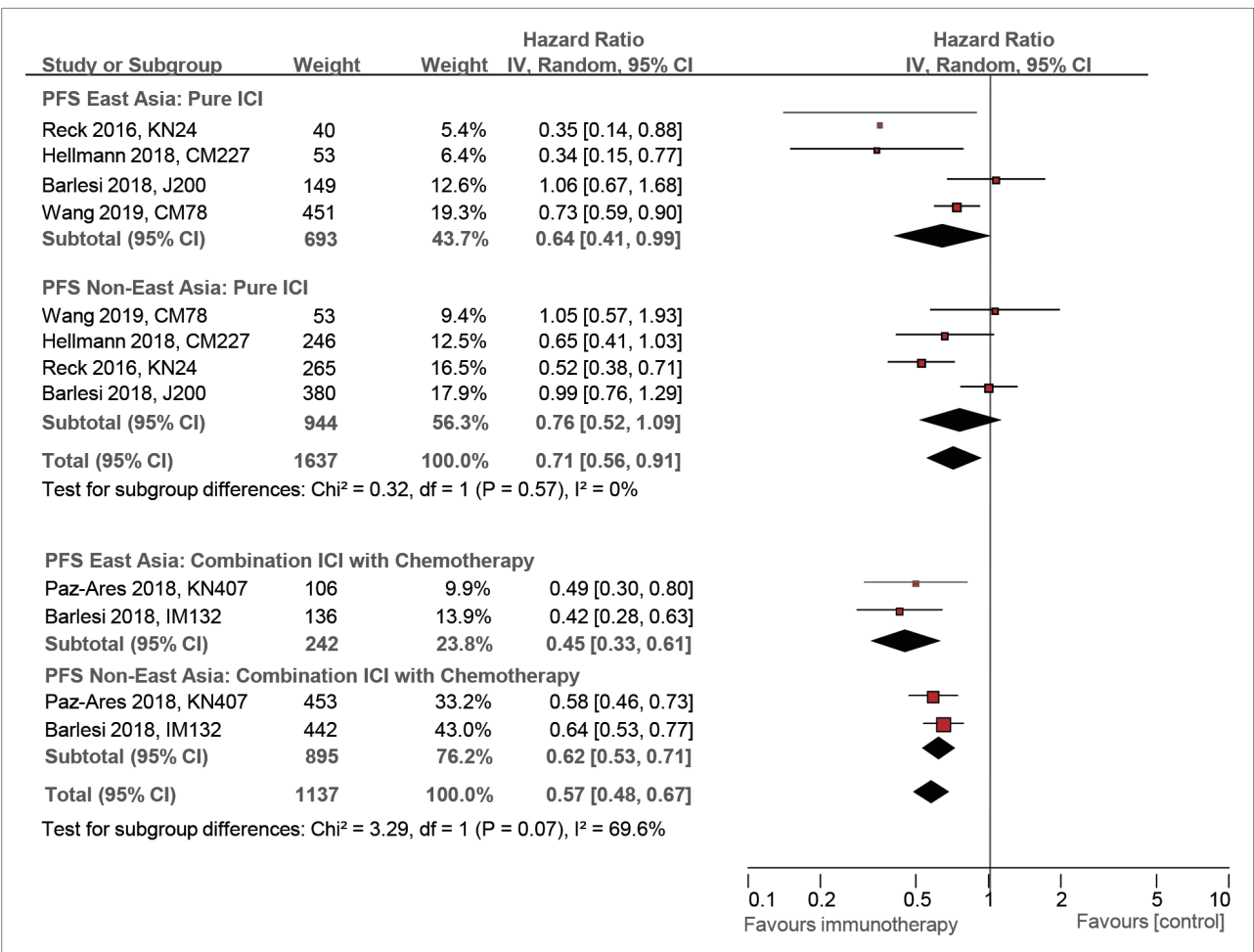

Figure 4 Comparison of regional subgroup difference in OS (A) and PFS (B) according to pure ICI versus combination therapy. 
between the two groups ( $\mathrm{P}$ for interaction $=0.57$ ). Similarly, in the ICI-chemotherapy combination subgroup, both East Asians (HR, 0.45; 95\% CI, 0.33-0.61) and non-East Asians (HR, 0.62; 95\% CI, 0.53-0.71) showed improved PFS with no difference between the two groups ( $\mathrm{P}$ for interaction $=0.07$ ).

\section{Discussion}

To the best of our knowledge, this is the first meta-analysis comparing the outcomes of immunotherapy in patients of advanced stage NSCLC from different geographical region. Our meta-analysis of seven RCTs showed that East Asian and non-East Asian patients responded similarly to ICI treatment, with no evidence of difference in the treatment effect. Our findings are consistent with a recently-published review paper that compared trial-level outcomes between studies done in predominant Caucasian populations with that in Asian (or Japanese) populations and concluded a lack of influence of ethnicity on response rate or survival outcomes (42).

There are multiple possible explanations for this. Firstly, due to the exclusion of EGFR/ALK mutation, which are more prevalent in East Asian patients and associated with poorer response to ICI $(8,10)$, the other differences between East Asian and non-East Asians were not significant enough to cause differential treatment response to ICIs. Alternatively, in the absence of the two predominant oncogene mutations, other potential predictors such as PD-L1 expression, TMB, tumour micro-environment and immune cell infiltration could have counteracted one another, thus giving East Asians the same response to ICIs as their non-East Asian counterparts. In addition, real world data has shown that PD-L1 expression is largely similar between East Asian and non-East Asian advanced NSCLC patients, giving rise to similar response to ICI (43).

Nonetheless, we recognise that there could potentially be unevaluated genetic differences between East Asian and non-East Asian advanced NSCLC patients that could lead to differential response to ICI. A recent analysis by Qian et al. using individual patient data from OAK and POPLAR $(44,45)$ has shown that Asians with previously-treated advanced NSCLC demonstrate longer OS (but not PFS) when treated with the PD-L1 antagonist atezolizumab, despite characteristics typically associated with lower immunogenicity such as a higher prevalence of EGFR mutation in Asians and a higher prevalence of smokers with higher blood TMB, PD-L1 expression and baseline sum of the longest tumour diameters in Whites (46). Qian proposes that this could be attributed to racial differences in genomic profiles, where the higher prevalence of serine/threonine kinase 11 (STK11) mutations in Caucasian patients (47) could result in their poorer response. However, the study was limited by the relatively small sample size and restricted genomic data that did not include deletion or copy number variations, and further studies are needed to explore racerelated genetic predictive factors of ICIs.

Next, it is possible that the small sample size within individual studies, with their wide CIs, may bias our results towards the null hypothesis (48). However, this is less likely because across the seven trials in this study, $32 \%$ of the patients $(n=1,740)$ are East Asians. Furthermore, our results are in line with data from trials with substantial East Asian recruitment, such as CheckMate-078 which comprises 89\% East Asians (29). Last but not least, it is possible that dilution effect may have occurred due to crossovers, since several of the included trials allow crossover between the control and experimental arms, and it is plausible that the rate of crossover may differ between geographical regions. However, we do not have the breakdown of crossover rates in East Asians and non-East Asians.

In further subgroup analysis, we noted that the East Asians seemed to exhibit better PFS than the non-East Asian when it came to first-line ICI therapy with an interaction $\mathrm{P}=0.02$ (Figure $3 B$ ). However, there was no significant regional difference in terms of OS among the same trials (Figure $3 A$ ). Although this was a pre-specified subgroup analysis, the result is limited by the small sample size and the lack of strong pre-existing biological rationale or correlation between similar survival outcomes. Therefore, while it is possible that there is some yetunknown mechanism that could explain the difference, it is far more likely that this statistical significance is due to chance (49).

The strengths of this meta-analysis include the strict inclusion criteria that required the comparison between immunotherapy and chemotherapy, rather than other targeted therapy or combination with radiation therapy, among patients with only Stage IIIB or IV NSCLC without EGFR mutation, and the rigorous up-to-date literature search. In addition, by pooling regional subgroups outcomes from individual RCTs, we were able to conduct more reliable comparisons where the East Asians and nonEast Asians had been randomised similarly in each trial (50). This is superior to comparing outcomes between trials conducted in purely one region versus another. Furthermore, we reduced inter-study heterogeneity by excluding trials 
with unclear definition of "Asia". This is necessary as we were unable to obtain individual patient data, we had to rely on the original regional classification adopted in each trial. Therefore, studies that did not have a pure Asia classification were excluded, for example, CheckMate-57 classified Latin America and Asia together in a subgroup called "Rest of the world" (51), while IMpower 131 classified Australia together with Asia under "Asia-Pacific" (52). We further provided the country of recruitment classified under Asia or East Asia, and noted the majority involved China, Japan and Korea (Table S2). Our analysis is also comprehensive as data was pooled from seven RCTs comprising 5,419 patients, with inclusion of trials with large number of East Asians like KEYNOTE-42 and CheckMate-078 $(25,29)$. As such, we can provide a specific yet comprehensive review that is up to date. Our method can also be applied to future meta-analysis when more data is available from the upcoming trials (Table S3).

This study has several limitations common to most metaanalysis and subgroup analyses (49). First, it used summary data rather than individual patient data. As a result, multiple Cox regression analysis to analyse the predictive effect of various biological or demographic confounders, such as histological subtypes, driver mutations, PD-L1 expression, age, sex and smoking status, could not be conducted. Second, analysis can only be conducted on published trials, thus introducing an inherent positive publication bias, since many trials that failed to reach the primary end-point of overall improvement in OS and/or PFS do not publish their results $(53,54)$. In addition, due to the relatively small number of trials available for further stratified subgroup analyses, meta-regression was not possible and our further subgroup outcomes may not be sufficiently powered to draw convincing conclusions (21). Lastly, within the broad East Asian versus non-East Asian classification, there are many different ethnic groups with different genetic and socioenvironmental make-up. Therefore, we need to exercise caution in applying population-level results to individual patients.

\section{Conclusions}

In summary, although East Asian advanced NSCLC patients possess a different clinical and genetic profile that has affected their response to some anti-cancer therapeutics, they respond well to CTLA-4 and PD-1/L1 inhibitors. However, the limitations of our study and the growing field of pharmacoethnicity highlight the increasing need for clinical trials in diverse populations to stratify results based on region or ethnicity in order to tease out sub-population level response to ICI.

\section{Acknowledgments}

Funding: None.

\section{Footnote}

Conflicts of Interest: All authors have completed the ICMJE uniform disclosure form (available at http:// dx.doi.org/10.21037/tlcr-20-246). BCT reports other from Boehringer Ingelheim Singapore Pte Ltd., Boehringer Ingelheim (Malaysia) Sdn Bhd and Wilely-Blackwell outside the submitted work. RS reports grants and personal fees from AstraZeneca and Boehringer Ingelheim, personal fees from Amgen, Bristol-Myers Squibb, Eli Lilly and Company, Merck \& Co., Novartis, Pfizer, F. Hoffmann-La Roche AG, Taiho Pharmaceutical, Takeda Pharmaceutical Company and Yuhan Co, Ltd. outside the submitted work. The other authors have no conflicts of interest to declare.

Ethical Statement: The authors are accountable for all aspects of the work in ensuring that questions related to the accuracy or integrity of any part of the work are appropriately investigated and resolved.

Open Access Statement: This is an Open Access article distributed in accordance with the Creative Commons Attribution-NonCommercial-NoDerivs 4.0 International License (CC BY-NC-ND 4.0), which permits the noncommercial replication and distribution of the article with the strict proviso that no changes or edits are made and the original work is properly cited (including links to both the formal publication through the relevant DOI and the license). See: https://creativecommons.org/licenses/by-nc-nd/4.0/.

\section{References}

1. Planchard D, Popat S, Kerr K, et al. Metastatic non-small cell lung cancer: ESMO Clinical Practice Guidelines for diagnosis, treatment and follow-up. Ann Oncol 2019;30:863-70.

2. Wu YL, Planchard D, Lu S, et al. Pan-Asian adapted Clinical Practice Guidelines for the management of patients with metastatic non-small-cell lung cancer: a CSCO-ESMO initiative endorsed by JSMO, KSMO, 
MOS, SSO and TOS. Ann Oncol 2019;30:171-210.

3. Peng L, Wu YL. Immunotherapy in the Asiatic population: Any differences from Caucasian population? J Thorac Dis 2018;10:S1482-93.

4. Zhou W, Christiani DC. East meets West: ethnic differences in epidemiology and clinical behaviors of lung cancer between East Asians and Caucasians. Chin J Cancer 2011;30:287-92.

5. Soo RA, Loh M, Mok TS, et al. Ethnic differences in survival outcome in patients with advanced stage non-small cell lung cancer: results of a meta-analysis of randomized controlled trials. J Thorac Oncol 2011;6:1030-8.

6. Chen J, Yang H, Teo ASM, et al. Genomic landscape of lung adenocarcinoma in East Asians. Nat Genet 2020;52:177-86.

7. Zhou F, Zhou C. Lung cancer in never smokers-the East Asian experience. Transl Lung Cancer Res 2018;7:450-63.

8. El-Osta H, Jafri S. Predictors for clinical benefit of immune checkpoint inhibitors in advanced non-small-cell lung cancer: a meta-analysis. Immunotherapy 2019;11:189-99.

9. Midha A, Dearden S, McCormack R. EGFR mutation incidence in non-small-cell lung cancer of adenocarcinoma histology: a systematic review and global map by ethnicity (mutMapII). Am J Cancer Res 2015;5:2892-911.

10. Lee CK, Man J, Lord S, et al. Clinical and Molecular Characteristics Associated With Survival Among Patients Treated With Checkpoint Inhibitors for Advanced NonSmall Cell Lung Carcinoma: A Systematic Review and Meta-analysis. JAMA Oncol 2018;4:210-6.

11. Mhanna L, Guibert N, Milia J, et al. When to Consider Immune Checkpoint Inhibitors in Oncogene-Driven Non-Small Cell Lung Cancer? Curr Treat Options Oncol 2019;20:60.

12. Cavanna L, Citterio C, Orlandi E. Immune checkpoint inhibitors in EGFR-mutation positive TKI-treated patients with advanced non-small-cell lung cancer network meta-analysis. Oncotarget 2019;10:209-15.

13. Berghoff AS, Bellosillo B, Caux C, et al. Immune checkpoint inhibitor treatment in patients with oncogeneaddicted non-small cell lung cancer (NSCLC): summary of a multidisciplinary round-table discussion. ESMO Open 2019;4:e000498.

14. Soo RA, Lim SM, Syn NL, et al. Immune checkpoint inhibitors in epidermal growth factor receptor mutant non-small cell lung cancer: Current controversies and future directions. Lung Cancer 2018;115:12-20.

15. Grizzi G, Caccese M, Gkountakos A, et al. Putative predictors of efficacy for immune checkpoint inhibitors in non-small-cell lung cancer: facing the complexity of the immune system. Expert Rev Mol Diagn 2017;17:1055-69.

16. Kuriakose A, Chirmule N, Nair P. Immunogenicity of Biotherapeutics: Causes and Association with Posttranslational Modifications. J Immunol Res 2016;2016:1298473.

17. Nazha B, Mishra M, Pentz R, et al. Enrollment of Racial Minorities in Clinical Trials: Old Problem Assumes New Urgency in the Age of Immunotherapy. Am Soc Clin Oncol Educ Book 2019;39:3-10.

18. Moher D, Liberati A, Tetzlaff J, et al. Preferred reporting items for systematic reviews and meta-analyses: the PRISMA statement. J Clin Epidemiol 2009;62:1006-12.

19. United Nations Statistics Division. Standard country or area codes for statistical use (M49). Available online: https://unstats.un.org/unsd/methodology/m49/. Accessed 6 February 2020.

20. Higgins JPT, Altman DG, Gøtzsche PC, et al. The Cochrane Collaboration's tool for assessing risk of bias in randomised trials. BMJ 2011;343:d5928.

21. Higgins J, Thomas J, Chandler J, et al. Cochrane Handbook for Systematic Reviews of Interventions version 6.0 (updated July 2019). July 2019. Available online: www. training.cochrane.org/handbook

22. Barlesi F, Nishio M, Cobo M, et al. IMpower132: efficacy of atezolizumab + carboplatin/cisplatin + pemetrexed as 1L treatment in key subgroups with stage IV non-squamous NSCLC. European Society for Medical Oncology (ESMO) 2018 Congress; Oct 22, 2018; Munich, Germany 2018. Available online: http://bit.ly/2QD5DTD

23. Barlesi F, Vansteenkiste J, Spigel D, et al. Avelumab versus docetaxel in patients with platinum-treated advanced non-small-cell lung cancer (JAVELIN Lung 200): an open-label, randomised, phase 3 study. Lancet Oncol 2018;19:1468-79.

24. Hellmann MD, Ciuleanu TE, Pluzanski A, et al. Nivolumab plus Ipilimumab in Lung Cancer with a High Tumor Mutational Burden. N Engl J Med 2018;378:2093-104.

25. Mok TSK, Wu YL, Kudaba I, et al. Pembrolizumab versus chemotherapy for previously untreated, PD-L1expressing, locally advanced or metastatic non-small-cell lung cancer (KEYNOTE-042): a randomised, open-label, controlled, phase 3 trial. Lancet 2019;393:1819-30.

26. Paz-Ares L, Luft A, Vicente D, et al. Pembrolizumab plus chemotherapy for squamous non-small-cell lung cancer. $\mathrm{N}$ Engl J Med 2018;379:2040-51.

27. Reck M, Rodriguez-Abreu D, Robinson AG, et al. Updated Analysis of KEYNOTE-024: Pembrolizumab 
Versus Platinum-Based Chemotherapy for Advanced NonSmall-Cell Lung Cancer With PD-L1 Tumor Proportion Score of 50\% or Greater. J Clin Oncol 2019;37:537-46.

28. Reck M, Rodriguez-Abreu D, Robinson AG, et al. Pembrolizumab versus Chemotherapy for PD-L1Positive Non-Small-Cell Lung Cancer. N Engl J Med 2016;375:1823-33.

29. Wang J. 2-Year Follow-up From CheckMate 078: Nivolumab Versus Docetaxel in a Predominantly Chinese Patient Population With Previously Treated Advanced Non-Small Cell Lung Cancer (NSCLC). The 22nd Annual Meeting of Chinese Society of Clinical Oncology; Sept 18-22; Xiamen China. 2019. Abstract Number: 5225.

30. Hellmann MD, Paz-Ares L, Bernabe Caro R, et al. Nivolumab plus Ipilimumab in Advanced Non-Small-Cell Lung Cancer. N Engl J Med 2019;381:2020-31.

31. Mok T, Wu Y, Kudaba I, et al. Final Analysis of the Phase 3 KEYNOTE-042 Study: Pembrolizumab vs PlatinumBased Chemotherapy as First-Line Therapy for Patients with PD-L1-Positive Locally Advanced or Metastatic NSCLC. Ann Oncol 2019;30:ii38-ii68.

32. Gogishvili M, Mobashery N, Makharadze T, et al. P2.01-26 EMPOWER-Lung 3: Phase 3 Study of Combinations of Cemiplimab and Chemotherapy in FirstLine Treatment of Advanced NSCLC. J Thorac Oncol 2019;14:S649.

33. Mok T, Johnson M, Garon E, et al. Poseidon: A phase 3 study of first-line durvalumab \pm tremelimumab + chemotherapy vs chemotherapy alone in metastatic NSCLC. J Thorac Oncol 2017;12:S1975.

34. Paz-Ares LG, Senan S, Planchard D, et al. Tislelizumab (BGB-A317) + concurrent chemoradiotherapy (cCRT) followed by tislelizumab monotherapy for newly diagnosed locally advanced, unresectable, stage III non-small cell lung cancer (NSCLC) in a phase III study (RATIONALE 001). J Clin Oncol 2019;37. doi: 10.1200/JCO.2019.37.15_ suppl.TPS8574.

35. Reck M, Yang CH, Postmus PE, et al. JAVELIN Lung 100: Updated design of a phase 3 trial of avelumab vs platinum doublet chemotherapy as first-line (1L) treatment for metastatic or recurrent PD-L11 non-small-cell lung cancer (NSCLC). Ann Oncol 2017;28:v492.

36. Rizvi N, Lee S, Curtis P, et al. EMPOWER-Lung 2: Cemiplimab and Ipilimumab \pm Chemotherapy vs Pembrolizumab in Advanced NSCLC with PD-L1 $\geq 50 \%$, a Phase 3 Study. J Thorac Oncol 2018;13:S931.

37. Spigel D, De Marinis F, Giaccone G, et al. IMpower110: Interim Overall Survival (OS) Analysis of a Phase III Study of Atezolizumab (Atezo) vs Platinum-based Chemotherapy (Chemo) as First-Line (1L) Treatment (Tx) in PD-L1selected NSCLC. Ann Oncol 2019;30:v851-v934.

38. Sriuranpong V, Altundag O, Clingan P, et al. EMPOWERlung 1: A randomized, open-label, multi-national, phase III trial of cemiplimab, a human PD-1 monoclonal antibody, versus chemotherapy in first-line treatment of advanced non-small cell lung cancer (NSCLC) with PD-L1 $\geq 50 \%$. Ann Oncol 2018;29:x39.

39. Wu YL, Lu S, Clarke S, et al. A phase 3 study of first-line durvalumab vs platinum-based chemotherapy in patients with advanced NSCLC and high PD-L1 expression: PEARL. Ann Oncol 2017;28:v492-3.

40. Zhou C, Caglevic C, Zhou J, et al. KEYNOTE-033: Phase 3 study of pembrolizumab versus docetaxel in patients with previously treated non-small-cell lung cancer (NSCLC). Ann Oncol 2017;28:x143.

41. Barlesi F, Nishio M, Cobo M, et al. IMpower132: Efficacy of atezolizumab (Atezo) 1 carboplatin (Carbo)/ cisplatin (Cis) 1 pemetrexed (Pem) as $1 \mathrm{~L}$ treatment in key subgroups with stage IV non-squamous non-small cell lung cancer (NSCLC). Ann Oncol 2018;29:viii743-viii4.

42. Lee J, Sun JM, Lee SH, et al. Are there any ethnic differences in the efficacy and safety of immune checkpoint inhibitors for treatment of lung cancer? J Thorac Dis 2019. doi: 10.21037/jtd.2019.08.29.

43. Dietel M, Savelov N, Salanova R, et al. 1300 Real-world prevalence of PD-L1 expression in locally advanced or metastatic non-small cell lung cancer (NSCLC): The global, multicentre EXPRESS study. J Thorac Oncol 2018;13:S74-5.

44. Fehrenbacher L, Spira A, Ballinger M, et al. Atezolizumab versus docetaxel for patients with previously treated non-small-cell lung cancer (POPLAR): a multicentre, open-label, phase 2 randomised controlled trial. Lancet 2016;387:1837-46.

45. Smith DA, Vansteenkiste JF, Fehrenbacher L, et al. Updated survival and biomarker analyses of a randomized phase II study of atezolizumab vs. docetaxel in $2 \mathrm{~L} / 3 \mathrm{~L}$ NSCLC (POPLAR). J Thorac Oncol 2016;34:abstr 9028.

46. Qian J, Nie W, Lu J, et al. Racial differences in characteristics and prognoses between Asian and white patients with nonsmall cell lung cancer receiving atezolizumab: An ancillary analysis of the POPLAR and OAK studies. Int J Cancer 2020;146:3124-33.

47. Zhang Y, Ma Y, Li Y, et al. Comparative analysis of cooccurring mutations of specific tumor suppressor genes in lung adenocarcinoma between Asian and Caucasian 
populations. J Cancer Res Clin Oncol 2019;145:747-57.

48. Hackshaw A. Small studies: strengths and limitations. Eur Respir J 2008;32:1141-3.

49. Yusuf S, Wittes J. Interpreting Geographic Variations in Results of Randomized, Controlled Trials. N Engl J Med 2016;375:2263-71.

50. Sun X, Ioannidis JP, Agoritsas T, et al. How to use a subgroup analysis: users' guide to the medical literature. JAMA 2014;311:405-11.

51. Borghaei H, Paz-Ares L, Horn L, et al. Nivolumab versus Docetaxel in Advanced Nonsquamous Non-Small-Cell Lung Cancer. N Engl J Med 2015;373:1627-39.

52. Socinski MA, Rittmeyer A, Shapovalov D, et al. IMpower131: Progression-free survival (PFS) and overall survival (OS) analysis of a randomised phase III study of

Cite this article as: Peng S, Ying AF, Tai BC, Soo RA. A metaanalysis on immune checkpoint inhibitor efficacy for advanced non-small cell lung cancer between East Asians versus nonEast Asians. Transl Lung Cancer Res 2020;9(4):1124-1137. doi: $10.21037 /$ tlcr-20-246 atezolizumab 1 carboplatin 1 paclitaxel or nab-paclitaxel vs carboplatin 1 nabpaclitaxel in $1 \mathrm{~L}$ advanced squamous NSCLC. Ann Oncol 2018;29:viii750-viii1.

53. AstraZeneca News. Update on the Phase III NEPTUNE trial of Imfinzi plus tremelimumab in Stage IV non-small cell lung cancer. AstraZeneca News. 21 August 2019. Available online: https://www.astrazeneca.com/mediacentre/press-releases/2019/update-on-the-phase-iiineptune-trial-of-imfinzi-plus-tremelimumab-in-stage-ivnon-small-cell-lung-cancer-21082019.html. Accessed 20 September 2019.

54. Riveros C, Dechartres A, Perrodeau E, et al. Timing and completeness of trial results posted at ClinicalTrials.gov and published in journals. PLoS Med 2013;10:e1001566. 


\section{Data sources and searches}

Two independent researchers (PS and AYF) conducted a comprehensive literature search in three databases: PubMedMEDLINE, Embase and Scopus. The dates searched were from the inception of each database to 20 September 2019.

We also reviewed abstracts and presentations from major conference proceedings in the past 5 years, including American Society of Clinical Oncology, World Conference on Lung Cancer and European Society for Medical Oncology from 2013 to September 2019.

When there are multiple reports of the same trial, we selected the most recent cohort with the largest sample size for analysis.

Differences in opinion were reconciled through discussion and consultation with an independent third party.

The search terms included:

- (“carcinoma, non-small-cell lung” OR "non-small cell lung cancer" OR "nsclc”);

- (“CTLA-4" OR “cytotoxic T-lymphocyte-associated protein 4" OR "PD-1" OR "PD-L1" OR "programmed death receptor 1" OR "immune checkpoint inhibitor" OR "ipilimumab” OR "tremelimumab” OR "nivolumab” OR "pembrolizumab” OR “atezolizumab” OR “durvalumab”).

The following filters were used in the respective databases

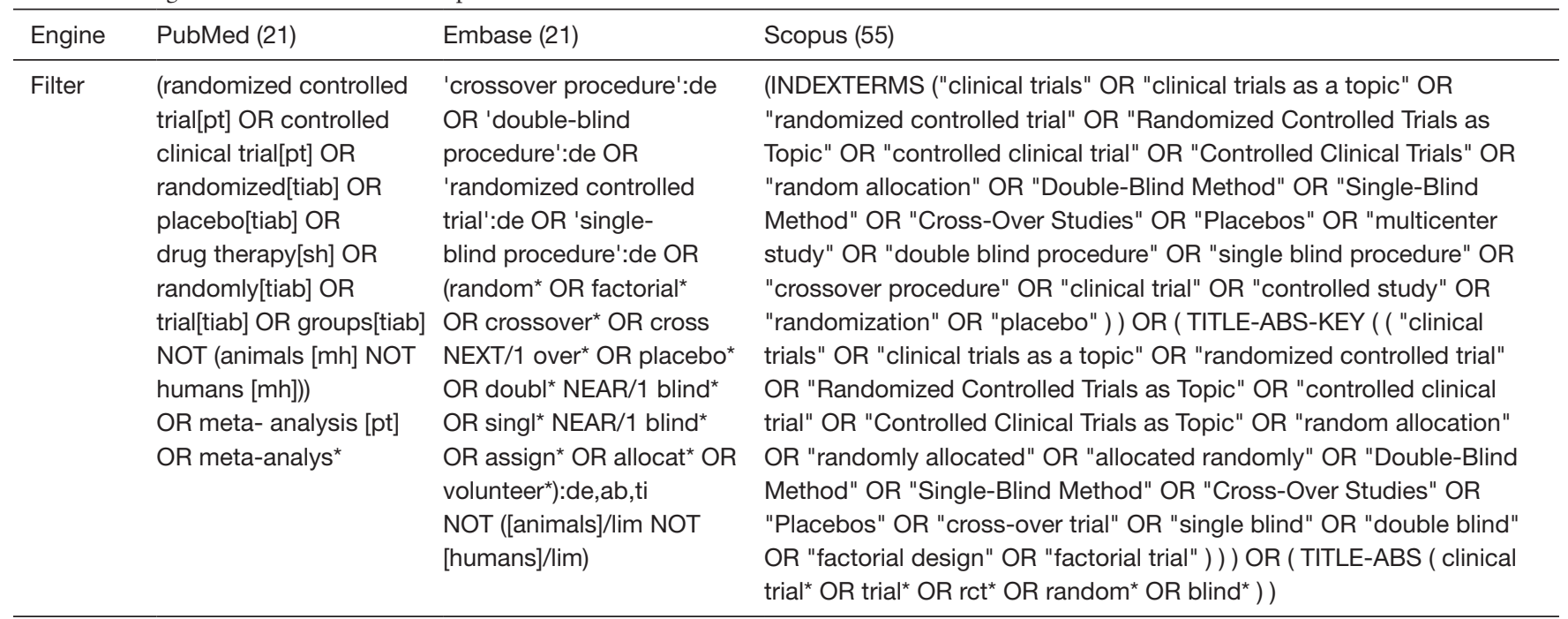

\section{Study selection and data extraction}

We selected all phase II and III Randomized Controlled Trials (RCT) that compared the use of Immune Checkpoint Inhibitors (ICI), either as monotherapy or in combination with another ICI or chemotherapy, versus chemotherapy.

The following inclusion criteria were applied with explanations provided for trials that were rejected:

(I) RCTs that recruited patients with advanced stage NSCLC (receiving palliative treatment).

The PACIFIC trial $(56,57)$ was excluded as it included patients with Stage III NSCLC who had received prior curative chemo-radiotherapy.

(II) RCTs evaluating in the treatment arm PD-1 and/or CTLA-4 inhibitors or their combination with ICI or chemotherapy.

Trials are excluded if they included in the treatment arm combination of ICI with other targeted therapy, e.g., combination of atezolizumab and bevacizumab in the treatment arm in IMpower 150 (58).

(III) RCTs comparing ICI with standard chemotherapy.

Trials are excluded if they compared the efficacy of one ICI versus another or different dosing of the same ICI agent, e.g., 
comparison of different duration and dosing of nivolumab treatment in CheckMate-153 (59) and CheckMate-384 (60) respectively.

(IV) Data available on hazard ratio (HR) for either OS or PFS or both according to regional subgroups in a single trial.

Trials that did not enroll any patients from East Asian regions were excluded, e.g., IMpower 130 (61), POPLAR (44) and CheckMate 17 (62).

Trials that were only conducted within a single country/region were excluded, e.g., Japanese only studies $(63,64)$ or isolated report of a single subgroup outcome [Japanese outcome in the OAK study (65)].

Trials that did not provide subgroup data by region despite enrollment from both East Asian and non-East Asian countries were excluded, e.g., KEYNOTE-10 (66), KEYNOTE-21G (67,68), KEYNOTE-189 (69), CheckMate-26 (70), ARCTIC (71) and a trial evaluating the effect of ipilimumab by Lynch $e t$ al. (72).

(V) RCT that recruited patients with EGFR/ALK mutation.

CheckMate-57 (51) and OAK (73) were excluded as they included patients with EGFR/ALK mutation and prior treatment with tyrosine kinase inhibitors.

(VI) RCT that did not have a pure "Asian" regional classification.

CheckMate-57 classified Latin America and Asia together in a subgroup called "Rest of the world" (51), while CA 184104 (Govindan et al.) (74) classified Asia under the "Other" category which include Australia and countries in Asia, Eastern Europe, or South America. Both trials were excluded.

IMpower 131 (52) and OAK (73) classified Australia and New Zealand respectively with Asia under "Asia-Pacific" and were excluded.

(VII) After the initial submission of our manuscript, we noted additional overall subgroup data of overall survival from the MYSTIC trial (75) newly published in April 2020. However, as the trial found both the Asian (HR 0.69; 95\% CI, 0.43-1.09) and non-Asian (HR 0.79; 95\% CI, 0.57-1.07) subgroups responded similarly (P for interaction $=0.64$ ) to durvalumab as compared to chemotherapy, and that it was only published after our writing, we did not include the result for analysis.

\section{Risk of bias assessment}

The study quality was assessed using the Risk of Bias tool (20) in Review Manager version 5.3 (RevMan 5.3) software, and scored according to the domains of selection bias, performance bias, detection bias, attrition bias and reporting bias. Publication bias was evaluated by funnel plots.

\section{Data synthesis and analysis}

Null hypothesis: there is no subgroup difference between patients from East Asia (EA) versus non-East Asia (non-EA), in terms of survival outcome of using Immune Checkpoint Inhibitors (ICI) as compared to chemotherapy in advanced NonSmall Cell Lung Cancer (NSCLC).

We extracted the HR and 95\% CI for Overall Survival (OS) and Progression Free Survival (PFS) separately for patients from all regional subgroups in each study. HR and CIs were log transformed and the corresponding variances obtained for calculating the pooled HR.

For studies that had more than two regional subgroups, we combined relevant groups into two big categories i.e., EA and non-EA, by using the fixed effect model to obtain a pooled estimate of survival (OS, PFS or both) from relevant regions. The fixed effect model was used in view of the general homogeneity within studies.

Then we pooled the HR for OS and PFS from various studies in EA and non-EA subgroups, using random-effect model. The $\log (\mathrm{HR})$ of each study was weighted by the inverse of its variance.

We used the Q-test to assess between study heterogeneity, which is presented in terms of $\mathrm{I}^{2}$ of heterogeneity.

To test the main hypothesis, we used the test of subgroup differences (chi square test) to determine if the $\mathrm{P}$ value of interaction was significant between the EA and non-EA subgroups in terms pooled HR for OS and PFS.

Lastly, we conducted further pre-specified subgroup analyses to explore the variation of the effect of region on the 
immunotherapy efficacy by the following variables:

(I) Line of therapy: first line $v s$. subsequent lines;

(II) Combination of treatment: pure immunotherapy (either single ICI or double ICI) vs. combination of immunotherapy with chemotherapy;

(III) Inclusion of patients with EGFR/ALK mutations.

All reported $\mathrm{P}$ values are 2 -sided. A $\mathrm{P}$ value of less than 0.05 was considered to indicate statistical significance. All analyses were performed with the RevMan 5.3 software.

A review protocol was created prior to the intervention but not registered online.

\section{References}

55. NUS Libraries. Systematic Reviews: Useful search filters by study design and topic. Searching Scopus for "Randomised Control Trials". 2019. Available online: http://libguides.nus.edu.sg/c.php?g=145717\&p=2470589

56. Antonia SJ, Villegas A, Daniel D, et al. Overall Survival with Durvalumab after Chemoradiotherapy in Stage III NSCLC. N Engl J Med 2018;379:2342-50.

57. Antonia SJ, Villegas A, Daniel D, et al. Durvalumab after chemoradiotherapy in stage III non-small-cell lung cancer. N Engl J Med 2017;377:1919-29.

58. Reck M, Mok TSK, Nishio M, et al. Atezolizumab plus bevacizumab and chemotherapy in non-small-cell lung cancer (IMpower150): key subgroup analyses of patients with EGFR mutations or baseline liver metastases in a randomised, open-label phase 3 trial. Lancet Respir Med 2019;7:387-401.

59. Spigel DR, McCleod M, Jotte RM, et al. Safety, Efficacy, and Patient-Reported Health-Related Quality of Life and Symptom Burden with Nivolumab in Patients with Advanced Non-Small Cell Lung Cancer, Including Patients Aged 70 Years or Older or with Poor Performance Status (CheckMate 153). J Thorac Oncol 2019;14:1628-39.

60. Garon E, Reinmuth N, Harris R, et al. CheckMate 384: A phase 3b/4 dose-frequency optimization trial of nivolumab in advanced or metastatic NSCLC. J Thorac Oncol 2018;13:S117-8.

61. West $\mathrm{H}, \mathrm{McCleod} \mathrm{M}$, Hussein M, et al. Atezolizumab in combination with carboplatin plus nab-paclitaxel chemotherapy compared with chemotherapy alone as first-line treatment for metastatic non-squamous non-small-cell lung cancer (IMpower130): a multicentre, randomised, open-label, phase 3. Lancet Oncol 2019;20:924-37.

62. Brahmer J, Reckamp KL, Baas P, et al. Nivolumab versus docetaxel in advanced squamous-cell non-small-cell lung cancer. N Engl J Med 2015;373:123-35.

63. Hida T, Nishio M, Nogami N, et al. Efficacy and safety of nivolumab in Japanese patients with advanced or recurrent squamous non-small cell lung cancer. Cancer Sci 2017;108:1000-6.

64. Nishio M, Hida T, Atagi S, et al. Multicentre phase II study of nivolumab in Japanese patients with advanced or recurrent nonsquamous non-small cell lung cancer. ESMO Open 2017;1:e000108.

65. Hida T, Kaji R, Satouchi M, et al. Atezolizumab in Japanese Patients With Previously Treated Advanced Non-Small-Cell Lung Cancer: A Subgroup Analysis of the Phase 3 OAK Study. Clin Lung Cancer 2018;19:e405-15.

66. Herbst RS, Baas P, Kim DW, et al. Pembrolizumab versus docetaxel for previously treated, PD-L1-positive, advanced nonsmall-cell lung cancer (KEYNOTE-010): A randomised controlled trial. Lancet 2016;387:1540-50.

67. Langer CJ, Gadgeel SM, Borghaei H, et al. Carboplatin and pemetrexed with or without pembrolizumab for advanced, nonsquamous non-small-cell lung cancer: a randomised, phase 2 cohort of the open-label KEYNOTE-021 study. Lancet Oncol 2016;17:1497-508.

68. Borghaei H, Langer CJ, Gadgeel S, et al. 24-Month Overall Survival from KEYNOTE-021 Cohort G: Pemetrexed and Carboplatin with or without Pembrolizumab as First-Line Therapy for Advanced Nonsquamous Non-Small Cell Lung Cancer. J Thorac Oncol 2019;14:124-9.

69. Gandhi L, Rodriguez-Abreu D, Gadgeel S, et al. Pembrolizumab plus Chemotherapy in Metastatic Non-Small-Cell Lung Cancer. N Engl J Med 2018;378:2078-92.

70. Carbone DP, Reck M, Paz-Ares L, et al. First-Line Nivolumab in Stage IV or Recurrent Non-Small-Cell Lung Cancer. N Engl J Med 2017;376:2415-26. 
71. Ferris RL, Even C, Haddad R, et al. Phase III, randomized, open-label study of durvalumab (MEDI4736) monotherapy, or durvalumab + tremelimumab, versus standard of care $(\mathrm{SoC})$, in recurrent or metastatic $(\mathrm{R} / \mathrm{M})$ squamous cell carcinoma of the head and neck (SCCHN): Eagle. J Immunother Cancer 2015;3:P150.

72. Lynch TJ, Bondarenko I, Luft A, et al. Ipilimumab in combination with paclitaxel and carboplatin as first-line treatment in stage IIIB/IV non-small-cell lung cancer: results from a randomized, double-blind, multicenter phase II study. J Clin Oncol 2012;30:2046-54.

73. Fehrenbacher L, von Pawel J, Park K, et al. Updated Efficacy Analysis Including Secondary Population Results for OAK: A Randomized Phase III Study of Atezolizumab versus Docetaxel in Patients with Previously Treated Advanced Non-Small Cell Lung Cancer. J Thorac Oncol 2018;13:1156-70.

74. Govindan R, Szczesna A, Ahn MJ, et al. Phase III Trial of Ipilimumab Combined With Paclitaxel and Carboplatin in Advanced Squamous Non-Small-Cell Lung Cancer. J Clin Oncol 2017;35:3449-57.

75. Rizvi NA, Cho BC, Reinmuth N, et al. Durvalumab With or Without Tremelimumab vs Standard Chemotherapy in First-line Treatment of Metastatic Non-Small Cell Lung Cancer. JAMA Oncol 2020;6:661-74. 
Table S1 Original regional distribution breakdown by region as described in the study

\begin{tabular}{|c|c|c|c|c|c|c|c|c|}
\hline Trial & $\begin{array}{c}\text { Total } \\
\text { number }\end{array}$ & Asia & $\begin{array}{l}\text { Non-East } \\
\text { Asia }\end{array}$ & $\begin{array}{c}\text { Rest of the } \\
\text { world }\end{array}$ & $\begin{array}{c}\text { USA \& Western } \\
\text { Europe }\end{array}$ & North America & Europe & Eastern Europe \\
\hline CheckMate 227 & 299 & 53 & NA & $52^{\ddagger}$ & NA & 30 & 164 & NA \\
\hline KEYNOTE-024 & 305 & 40 & 265 & NA & NA & NA & NA & NA \\
\hline JAVELIN Lung 200 & 529 & 149 & NA & $132^{\S}$ & 141 & NA & NA & 107 \\
\hline IMpower 132 & 578 & 136 & 442 & NA & NA & NA & NA & NA \\
\hline Sum of region & 5,465 & 1,740 & 3,099 & 184 & 141 & 30 & 164 & 107 \\
\hline
\end{tabular}

${ }^{\dagger}$, Chinese, non-Chinese classification; ${ }^{\ddagger}$, rest of the world in in CM227 [2018]: Argentina, Australia, Brazil, Chile, Colombia, Israel, Lebanon, Mexico, Peru, Turkey and South Africa; ${ }^{\S}$, rest of the world in JAVELIN Lung 200 [2018]: South America and Africa. NA, not applicable.

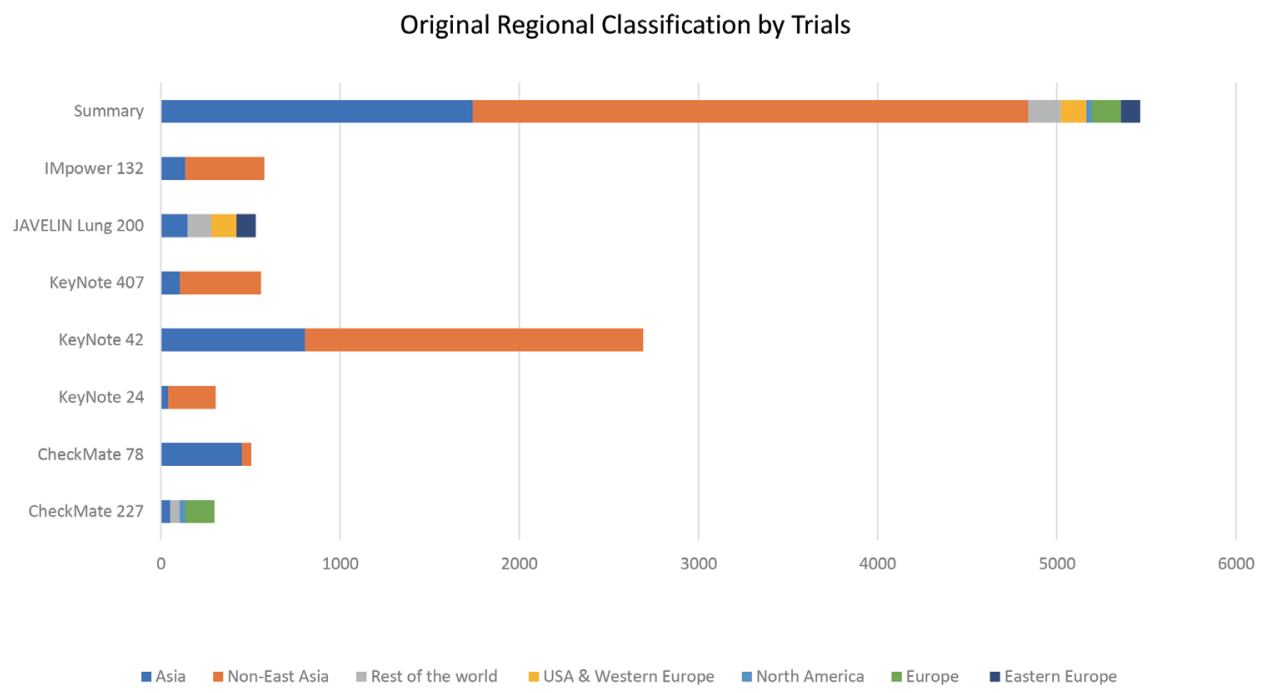

Figure S1 Original regional classification by trials. 


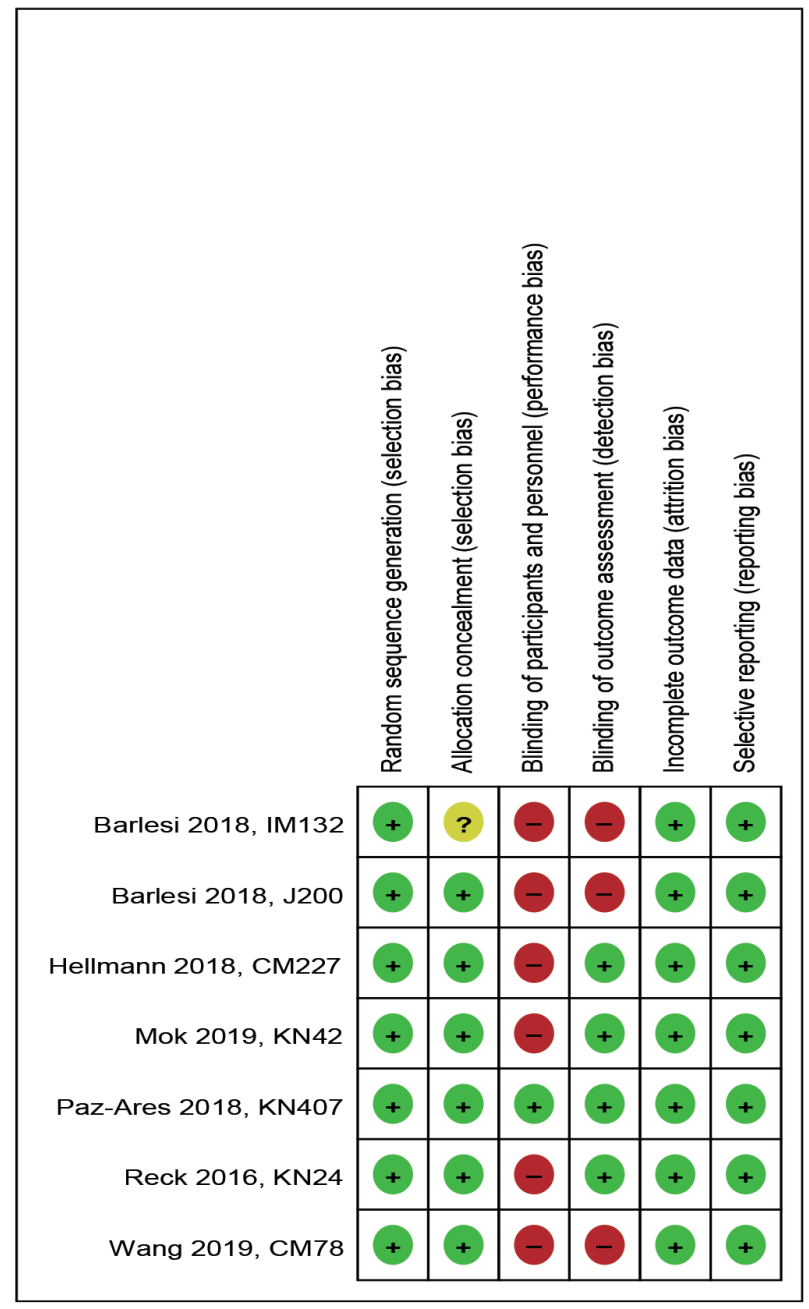

Figure S2 Risk of bias summary.
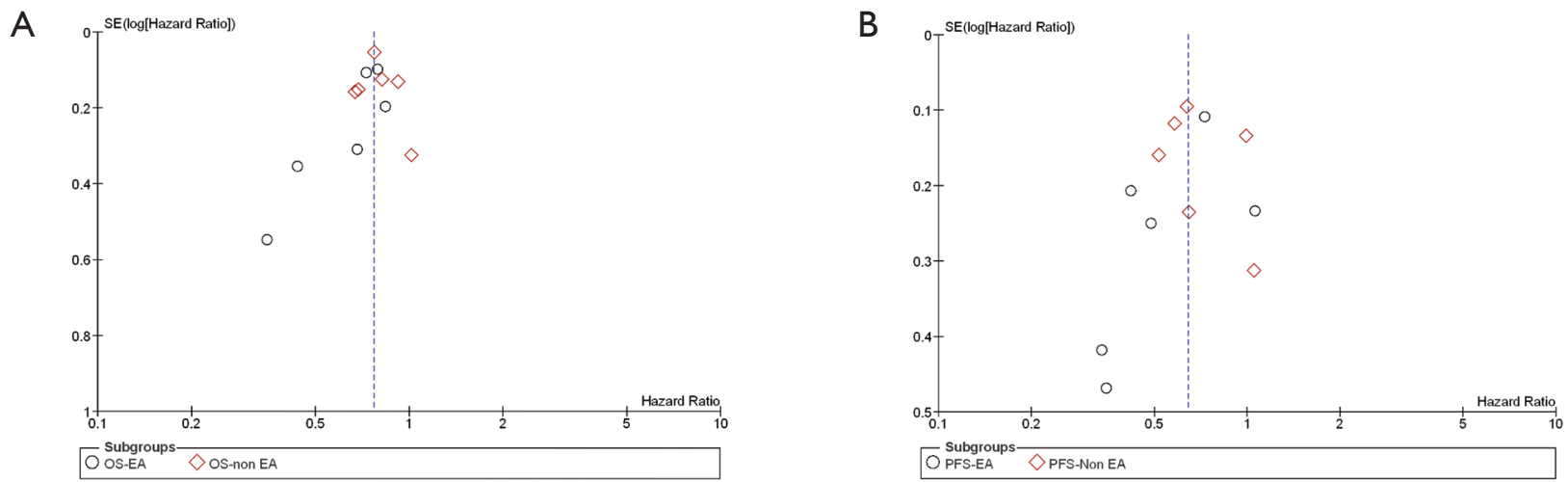

Figure S3 Analysis of publication bias (funnel plot): OS (A) and PFS (B) in East Asian versus non-East Asian. 


\begin{tabular}{|c|c|c|c|c|c|c|c|}
\hline Trials & East Asia or Asia-Pacific ${ }^{*}$ & Oceania & North/Western Europe & Eastern Europe/Middle East & North America & Latin America & Africa \\
\hline CheckMate 227 & Japan, Republic of Korea, Taiwan & Australia & $\begin{array}{l}\text { Austria, Belgium, Finland, France, Germany, Ireland, Italy, } \\
\text { Netherlands, Spain, Switzerland, UK }\end{array}$ & $\begin{array}{l}\text { Poland, Hungary, Greece, Czech Republic, Israel, } \\
\text { Lebanon, Turkey, Russian Federation, Romania }\end{array}$ & USA, Canada & $\begin{array}{l}\text { Argentina, Brazil, Chile, Colombia, Mexico, } \\
\text { Peru }\end{array}$ & South Africa \\
\hline CheckMate 078 & China, Singapore & & & Russian Federation & & & \\
\hline KEYNOTE-024 & Japan & $\begin{array}{l}\text { Australia, New } \\
\text { Zealand }\end{array}$ & $\begin{array}{l}\text { Austria, Belgium, France, Germany, Ireland, Italy, } \\
\text { Netherlands, Spain, UK }\end{array}$ & Hungary, Israel & USA, Canada & & \\
\hline KEYNOTE-407 & China, Japan, Republic of Korea, Thailand & Australia & France, Germany, Italy, Netherlands, Spain & Hungary, Poland, Turkey, Russian Federation & USA, Canada & Mexico & \\
\hline KEYNOTE-042 & $\begin{array}{l}\text { China, Hong Kong, Japan, Malaysia, Philippines, Republic of } \\
\text { Korea, Taiwan, Thailand, Vietnam }\end{array}$ & & Estonia, Latvia, Lithuania, Portugal, Sweden, Switzerland & $\begin{array}{l}\text { Czech Republic, Hungary, Romania, Ukraine, Russian } \\
\text { Federation, Turkey }\end{array}$ & Canada & $\begin{array}{l}\text { Argentina, Brazil, Bulgaria, Chile, Mexico, } \\
\text { Peru, Guatemala, Colombia }\end{array}$ & South Africa \\
\hline \multicolumn{2}{|c|}{ JAVELIN Lung 200 Japan, Republic of Korea, Taiwan } & Australia & $\begin{array}{l}\text { Italy, UK, Belgium, France, Spain, Denmark, Estonia, } \\
\text { Switzerland, Latvia }\end{array}$ & $\begin{array}{l}\text { Turkey, Romania, Russian Federation, Bulgaria, Croatia, } \\
\text { Poland, Hungary, Czech Republic }\end{array}$ & USA & $\begin{array}{l}\text { Chile, Peru, Colombia, Mexico, Brazil, } \\
\text { Argentina }\end{array}$ & South Africa \\
\hline IMpower 132 & China, Japan, Republic of Korea, Malaysia, Taiwan & Australia & $\begin{array}{l}\text { Austria, Belgium, France, Ireland, Italy, Latvia, Lithuania, } \\
\text { Netherlands, Portugal, Spain, UK }\end{array}$ & $\begin{array}{l}\text { Bulgaria, Hungary, Israel, Romania, Russian Federation, } \\
\text { Ukraine }\end{array}$ & USA & Argentina, Chile, Peru & \\
\hline
\end{tabular}


Table S3 Upcoming trials that recruited from Asia

\begin{tabular}{|c|c|c|c|c|c|c|c|c|c|c|}
\hline Study & NCT \# & Phase & $\begin{array}{c}\text { Comparison } \\
\text { groups }\end{array}$ & Line & Stage & $\begin{array}{c}\text { EGFR/ALK } \\
\text { mutation }\end{array}$ & $\begin{array}{c}\text { PD-L1 } \\
\text { expression }\end{array}$ & $\begin{array}{c}\text { Total } \\
\text { patients }\end{array}$ & $\begin{array}{l}\text { Primary } \\
\text { outcome }\end{array}$ & $\begin{array}{c}\text { Estimated } \\
\text { completion } \\
\text { date }\end{array}$ \\
\hline $\begin{array}{l}\text { RATIONALE } \\
001(34)\end{array}$ & NCT03358875 & 3 & $\begin{array}{c}\text { Chemotherapy } \\
\text { Tislelizumab }\end{array}$ & $>1$ & IIIB or IV & None & Any & 800 & OS (2nd: PFS) & Dec 2020 \\
\hline $\begin{array}{l}\text { EMPOWER- } \\
\text { Lung } 1 \text { (38) }\end{array}$ & NCT03088540 & 3 & $\begin{array}{l}\text { Chemotherapy } \\
\text { Cemiplimab }\end{array}$ & 1 & $\begin{array}{l}\text { IIIB, IIIC, } \\
\text { IV }\end{array}$ & $\begin{array}{c}\text { None (also } \\
\text { no ROS1) }\end{array}$ & $\geq 50 \%$ & 700 & PFS (2nd: OS) & Feb 2023 \\
\hline $\begin{array}{l}\text { EMPOWER- } \\
\text { Lung } 2 \text { (36) }\end{array}$ & $\begin{array}{c}\text { EudraCT 2017- } \\
001041-27\end{array}$ & 3 & $\begin{array}{l}\text { Pembrolizumab } \\
\text { Cemiplimab + } \\
\text { Ipilimumab } \\
\text { Cemiplimab } \\
\text { + Platinum } \\
\text { chemotherapy }\end{array}$ & 1 & IIIB, IV & Any & $\geq 50 \%$ & 585 & PFS & Feb 2023 \\
\hline $\begin{array}{l}\text { EMPOWER- } \\
\text { Lung } 3 \text { (32) }\end{array}$ & NCT03409614 & 3 & $\begin{array}{c}\text { Chemotherapy + } \\
\text { placebo } \\
\text { Cemiplimab + } \\
\text { Chemotherapy } \\
\text { Cemiplimab } \\
+ \text { abbreviated } \\
\text { chemotherapy + } \\
\text { Ipilimumab }\end{array}$ & 1 & $\begin{array}{l}\text { IIIB, IIIC, } \\
\text { IV }\end{array}$ & $\begin{array}{c}\text { None (also } \\
\text { no ROS1) }\end{array}$ & $<50 \%$ & 810 & PFS, OS & Feb 2023 \\
\hline $\begin{array}{l}\text { POSEIDON } \\
\text { (33) }\end{array}$ & NCT03164616 & 3 & $\begin{array}{l}\text { Chemotherapy } \\
\text { Durvalumab + } \\
\text { Chemotherapy } \\
\text { Chemotherapy } \\
\text { + Durvalumab + } \\
\text { Tremelimumab }\end{array}$ & 1 & IV & None & Positive & 1,000 & PFS, OS & Apr 2021 \\
\hline
\end{tabular}

